\title{
Glucosylceramide transfer from lysosomes-the missing link in molecular pathology of glucosylceramidase deficiency: A hypothesis based on existing data
}

\author{
M. Elleder
}

Received: 7 June 2006 / Submitted in revised form: 11 September 2006 / Accepted: 25 September 2006 / Published online: 2 November 2006 (C) SSIEM and Springer 2006

Summary Gaucher disease (GD), deficiency of acid glucosylceramidase (GlcCer-ase) is characterized by deficient degradation of beta-glucosylceramide (GlcCer). It is well known that, in GD, the lysosomal accumulation of uncleaved GlcCer is limited to macrophages, which are gradually converted to storage cells with well known cytology — Gaucher cells (GCs). On the basis of previous studies of the disorder and of a comparison with other lysosomal enzymopathies affecting degradation of the GlcCer-based glycosphingolipid series, it is hypothesized that in other cell types (i.e. nonmacrophage cells) the uncleaved GlcCer, in GlcCer-ase deficiency, is transferred to other cell compartments, where it may be processed and even accumulated to various degrees. The consequence of the abnormal extralysosomal load may differ according to the cell type and compartment targeted and may be influenced by genetically determined factors, by a number of acquired conditions, including the current metabolic situation. The sequelae of the uncleaved GlcCer extralysosomal transfer may range from probably innocent or positive stimulatory, to the much more serious, in which it interferes with a variety of cell functions, and in extreme cases, can lead to cell death. This alternative processing of uncleaved GlcCer may help to explain tissue alterations seen in GD that have, so far, resisted explanation based simply on the presence of GCs. Paralysosomal alternative processing

Communicating editor: Guy Besley

Competing interests: None declared

Presented at the EWGGD meeting, Cambridge UK, 18-22 July 2006

M. Elleder

Institute of Inherited Metabolic Disorders, Charles University

Prague, 1st Faculty of Medicine and University Hospital, Bldg. D,

Division B, Ke Karlovu 2, 12808 Prague 2, Czech Republic

e-mail: melleder@cesnet.cz may thus go a long way towards filling a long-standing gap in the understanding of the molecular pathology of the disorder. The impact of this alternative process will most likely be inversely proportional to the level of residual GlcCer-ase activity. Lysosomal sequestration of GlcCer in these cells is either absent or in those exceptional cases where it does occur, it is exceptional and rudimentary. It is suggested that paralysosomal alternative processing of uncleaved GlcCer is the main target for enzyme replacement therapy. The mechanism responsible for GlcCer transfer remains to be elucidated. It may also help in explaining the so far unclear origin of glucosylsphingosine (GlcSph) and define the mutual relation between these two processes.
Abbreviations
CCT CTP: phosphocholine cytidylyltransferase
ERT enzyme replacement therapy
GCs Gaucher cells
GD Gaucher disease
GlcCer beta-glucosylceramide
GlcSph glucosylsphingosine

\section{The current state of knowledge on Gaucher disease}

Gaucher disease (GD) is a disease defined by deficient catalytic activity of acid glucosylceramidase (GlcCer-ase). From the molecular genetics perspective, it is caused by a mutation in the gene coding for the enzyme that interferes with its production, catalytic activity and transport along its secretory pathway. Additionally, the absence of the specific activator of GlcCer-ase, saposin C, may be responsible for the Gaucher phenotype. At the cellular and lipid biochemical levels, GD is characterized by beta-glucosylceramide (GlcCer) storage that is restricted to the lysosomes of macrophages. 
Therefore, GD is classified as a macrophage-specific glycosphingolipidosis despite numerous tissue alterations described, for example, in the central nervous system and epidermis, especially in severe infantile variants (see below). GlcCer storage is paralleled by an increase in its lysoderivative (GlcSph), the origin of which is still uncertain and which is considered to be responsible cell degeneration in profound GlcCer-ase deficiency. Further details together with description of the spectrum of phenotypes are summarized in a number of articles and monographs (Beutler et al 2001; Cox and Schofield 1997; Desnick et al 1982; Ginzburg et al 2004; Ron and Horowitz 2005; Schmitz et al 2005; Zhao and Grabowski 2002).

\section{The persistent enigma of the cellular pathology of GlcCer-ase deficiency}

Despite being first described over one and a quarter centuries ago, and recognized as a $\mathrm{GlcCer}$ storage disease since 1934 (Aghion 1934), the cell pathology of GlcCerase-deficient cells is intriguing and fundamentally different from that of other lysosomal storage disorders. It is important to realize that GlcCer and other glycolipids are widely distributed in tissues (Suzuki 1982) and are concentrated mainly in the plasmalemma (http://www. glycoforum.gr.jp/science/word/glycolipid/GLA01E.html). At the same time, GlcCer is the final step in the glycolipid (ganglio-, globo-, lacto-, and haemato- series) degradative pathway (Ginzburg et al 2004). It is clear, therefore, that its lysosomal turnover must be of very high order, most likely the highest out of the entire glycosphingolipid family. It rationally follows that a deficiency in GlcCer-ase should manifest itself by a high level of lysosomal storage of GlcCer with a notable tendency towards generalization, producing a situation similar to that seen in the profound deficiency of acid sphingomyelinase in classical Niemnann-Pick disease type A (Elleder 1989; Schuchman and Desnick 2001).

However, a simple comparison with other lysosomal glycolipid storage disorders resulting from reduced degradation of the glycosphingolipid series, with GlcCer as the ultimate step in the degradation process, reveals striking differences. For instance, Fabry disease ( $\alpha$-galactosidase deficiency) is characterized by intensive $\mathrm{Gb}_{3}$ Cer lysosomal storage in many different types of cells, e.g. endothelium, smooth-muscle cells, glomerular podocytes, cardiocytes, etc. This reflects the high degradation rate of the globo series lipids in these (and other) cells. The degradation of $\mathrm{Gb}_{3} \mathrm{Cer}$ is normally followed by $\beta$-galactosidase, cleaving lactosylceramide, and GlcCer-ase, cleaving GlcCer. Surprisingly, all these cells are free from the lysosomal storage in GD (endothelial cells in dermal capillaries studied in a case of infantile GD displayed pronounced changes characterized as a combination of de- generation and regeneration, without any lysosomal storage; unpublished personal observations). Similarly intensive neurolysosomal storage in both $\mathrm{GM}_{2}$ and $\mathrm{GM}_{1}$ gangliosidoses points to high lysosomal turnover of this glycosphingolipid series, again with GlcCer as a final step in the degradation process. It is well known that neurons in GD are either unaffected or degenerate with little or no sign of GlcCer lysosomal storage (see below). All the existing data point to absence of lysosomal storage in cells generally, except for macrophages, irrespective of the severity of the defect (Mizukami et al 2002; Tybulewicz et al 1992; Willemsen et al 1995; Xu et al 2003). To conclude, GCs are considered to be the main pathological event in GD (Beutler and Grabowski 2001; Lee 1982; Parkin and Brunning 1982). However, the protean manifestations of the disorder (Moran et al 2000; Sidransky 2004) is difficult to explain by the mere presence of Gaucher cells (GCs).

Part of the tissue damage seen in GD is thought to be explained by the toxic GlcCer lysoderivative GlcSph. This compound, normally present in trace amounts, can increase several hundred-fold in various tissues in GD (see below).

\section{The proposed hypothesis}

On the basis of the above-mentioned enigma, it is suggested that besides the well-known lysosomal sequestration of uncleaved GlcCer in GlcCer-ase deficiency, there must be an alternative pathway for its disposal existing in all other cells that have GlcCer lysosomal turnover. In these non-macrophage cells the uncleaved GlcCer is believed to be transferred from lysosomes to other cell compartments where it may undergo processing or perhaps even be accumulated to varying degrees (extralysosomal 'storage'). This mechanism explains the general absence of detectable lysosomal storage of GlcCer in non-macrophage cells. It may also be responsible for the plethora of symptoms that could never be explained by the presence of GCs alone. The alternative processing of the uncleaved GlcCer may include, along with other mechanisms, induction of GlcSph production. The relationship between the paralysosomal destination of uncleaved GlcCer (not leading to lysosomal storage), the mode of its processing and its lysosomal destination (leading to lysosomal storage) may lead to a better understanding of the 'phenotypic complexity of this simple disorder,' as aptly described by Sidransky in a recent report (Sidransky 2004). It should focus attention much more on studies of 'nonstoring cells' in GlcCer-ase deficiency.

According to the proposed hypothesis, the fate of the uncleaved GlcCer can follow one of two pathways-the newly proposed one, characterized by its extralysosomal transfer and alternative processing in nonlysosomal cell compartments of non-macrophages, and the classic one characterized 
Fig. 1 Scheme of the proposed fate of uncleaved glucocerebroside in glucocerebrosidase deficiency, including the possible routes of glucosylsphingosine generation

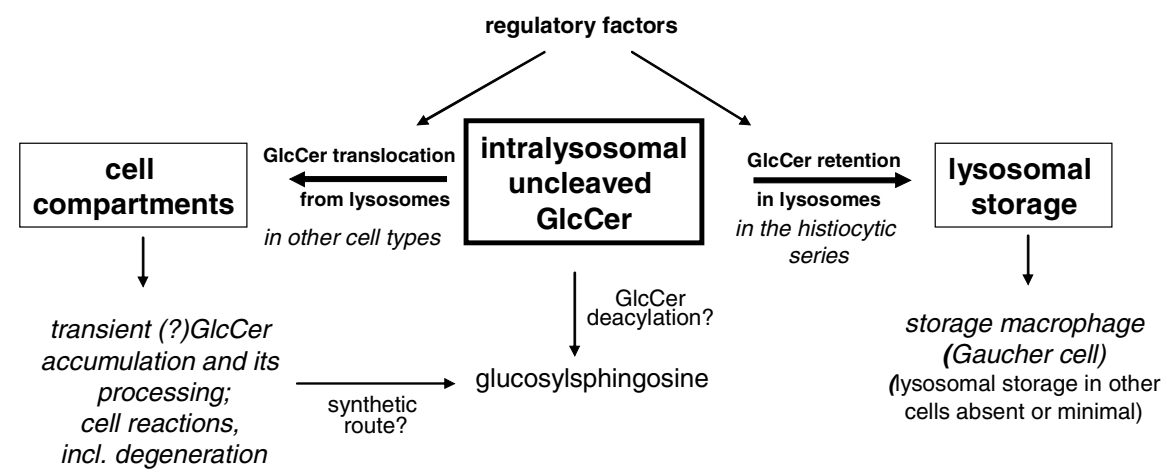

by its accumulation in the lysosomal compartment of macrophages (Fig. 1). A discussion of both pathways follows.

\section{Glucosylceramide transfer}

The amount of translocated GlcCer, which is determined by the degree of GlcCer-ase deficiency, may represent a specific and virtually permanent glycolipid load to cell compartments. The consequence of this abnormal load of GlcCer is likely to differ based on cell type and the compartment targeted and may also be influenced by genetically determined factors as well as by a number of acquired conditions, including the current metabolic situation. The sequelae of the translocation of uncleaved GlcCer may range from those that have little or no effect (either positive or negative) to those that are quite serious, interfering with cell biology and, in extreme cases, leading to cell death. Under these conditions, GlcCer is not stored within lysosomes but may instead be accumulated only transiently extralysosomally, then either degraded or used as substrate for the synthesis of more complex glycolipids known to be increased in GD spleens (Nilsson et al 1982).

The hypothesis fits well with experiments carried out on cultured mutant fibroblasts from GD patients. These cells were able to take up, but not to degrade, radioactively labelled GlcCer. At the same time, they avoided lysosomal storage of GlcCer by transferring it to anabolic compartments where it was converted into more complex glycosphingolipids (Barton and Rosenberg 1975; Saito and Rosenberg 1985). Similarly, GlcCer generated from radioactively labelled lactosylceramide degradation in rat liver lysosomes was found to reach the Golgi apparatus where it underwent glycosylation (Trinchera et al 1991). Moreover, results of detailed biochemical analysis of neurons in neuronopathic GD are suggestive of GlcCer exit from neurolysosomes (see below).

The hypothesis presented helps in understanding many symptoms of the GD phenotype that cannot be explained by the mere presence of GCs; first of all the discrepancy be- tween the severe symptomatology and organ damage especially in perinatal-lethal devastating variants of GD (Mignot et al 2003; Sidransky et al 1992) and in the mouse model of GD created by targeted disruption of GlcCer-ase gene (Tybulewicz et al 1992), characterized by profound GlcCerase deficiency.

In patients with types II and III GD neuronal degeneration occurs without any or with a rudimentary degree of lysosomal storage, even at the ultrastructural level (Adachi et al 1967; Cervos-Navarro and Zimmer 1990; Conradi et al 1991, 1988; Grafe et al 1988; Hernandez and Bueno 1973; Lloyd et al 1956). I would like to stress the tendency to general extensive proliferation of astrocytes independently of neuronal degeneration and perivascular GCs (Cervos-Navarro and Zimmer 1990). The neuronal degeneration has been shown to be associated with increased levels of GlcCer in the neuronal endoplasmic reticulum and with abnormally enhanced agonist-induced calcium release from GD type II brain microsomes, which served to make the neurons more sensitive to glutamate-induced neurotoxicity. Similarly, in the neuronal models of GD, it was shown that GlcCer directly activated phospholipid synthesis by activation of CTP:phosphocholine cytidylyltransferase (CCT), which was shifted from cytosol to the endoplasmic reticulum (Bodennec et al 2002; Korkotian et al 1999; Pelled et al 2005). All these phenomena could be explained by the transfer of the uncleaved lysosomal GlcCer into the neuronal endoplasmic reticulum (Bodennec et al 2002; Jmoudiak and Futerman 2005). The role of GlcSph in neuronal degeneration is mentioned below.

It should be stressed that the electron-microscopic studies of GD II done in the past described significant alterations in the neuronal endoplasmic reticulum and its suggestive connection with the discrete lysosomal storage compartment (Adachi et al 1967). Similar connections were observed in neurons in mouse experimental GD induced by conduritol B epoxide storage (Adachi and Volk 1977).

The permanent influx of GlcCer into the endoplasmic reticulum-Golgi complex may lead to dysregulation of the 'glycosphingolipid-dependent cell fate program in cancer 
and stem cells' (Bieberich 2004). This may explain the B lymphocyte stimulation and increased incidence of myeloma (Fox et al 1984; Zimran et al 2005) and offer evidence of the pro-mitogenic effect of translocated, uncleaved GlcCer. The B cell hyperproliferation described in experimentally induced GD in adult mice is in accordance with these observations (Mizukami et al 2002). The growth-promoting effect of GlcCer described in various experiments, leading to its increased cellular content (Bieberich 2004; Datta and Radin 1988; Hara and Radin 1979; Marsh et al 1995; Shayman et al 1991; Uchida et al 2002), may help to explain the large increase in the volume of organs which, in infantile variants, cannot be explained purely by presence of GCs (Cox 2001; Zhao and Grabowski 2002).

It should be mentioned that the serum markers for GD (Cox 2005; Deegan et al 2005) are considered to be produced and secreted by GCs (Hollak et al 1994), with the exception of the hex B marker, which has been suggested to come from hepatocytes (Casal et al 2002) altered by GlcCerase deficiency. It is worth noting that a massive systemic inflammation syndrome was induced in adult mice carrying the GD L444P mutation, which at the same time showed only minimal storage of GlcCer. This suggests a substantial degree of independence of the described cytokine storm of GCs (Mizukami et al 2002).

There are several other examples of organ damage in various forms of GD where the proposed effects of the paralysosomal translocation of uncleaved GlcCer may play an important role. It is likely to play a role in the serious skin symptomatology seen in perinatal GD, described as 'collodion baby' (Lipson et al 1991) or ichthyosis (Sherer et al 1993), which is currently explained as being caused by a decrease in ceramide normally released from GlcCer in the terminal part of epidermis by GlcCer-ase. The altered ratio of GlcCer to ceramides leads to an alteration of the hydrophobic barrier, decreased keratinocyte desquamation (Eblan et al 2005; Holleran et al 1994; Sidransky et al 1992) and their increased proliferation (Marsh et al 1995). Further, the myocardial involvement observed in GD (Platzker et al 1985; Torloni et al 2002) has been explained solely by the infiltration of the heart by GCs (Edwards et al 1983; Smith et al 1978), while the syndrome of pulmonary hypertension is thought to be caused by GCs occupying the lumina of the alveolar capillaries or alveoli (Mistry et al 2002), although this syndrome has been described in the absence pulmonary GCs (Theise and Ursell 1990). Lastly, bone involvement leading to 'bone crises' (Beighton et al 1982) is also awaiting an explanation that goes beyond the mere presence of GCs (Fiore et al 2002; Stowens et al 1985; Wenstrup et al 2002). The enhanced expression of cysteine proteinases in GCs and other cells might contribute to lytic bone lesions (Moran et al 2000). The effect of the paralysosomal GlcCer load is worth exploring in the repeatedly reported atypical complex and atypical phenotypes of GD (Bodamer et al 2002; George et al 2001; Inui et al 2001; Stone et al 2000; Uyama et al 1992; Wilson et al 1985) and even in the evolution of Parkinson syndrome in GD (Tayebi et al 2003; Wong $\mathrm{K}$ et al 2004). Further manifestations of the expanding phenotypic spectrum are mentioned in a recent survey (Sidransky 2004).

The only present mechanism of tissue damage in GD is considered to be GlcSph, which differs from the stored GlcCer by absence the fatty acid. This compound with wellrecognized toxicity (reviewed by Orvisky et al 2002), present in normal tissues in trace amounts, can increase several hundred-fold in various tissues in GD (Nilsson et al 1982; Orvisky et al 2000, 2002). Its accumulation is considered to be responsible for the devastating clinical course of patients with the infantile type of Gaucher disease (Orvisky et al 2000, 2002), especially for the neuronal damage (Schueler et al 2003). Its levels, however, are considered to be below those required for induction of the reported toxic effects related to GlcCer. As such, the observed neurotoxicity must involve a different mechanism (Lloyd-Evans et al 2003). The exact site of its origin, lysosomal deacylation or deficient acylation in the endoplasmic reticulum, is still not clear (Orvisky et al 2000). Both pathways were suggested to be responsible (Yamaguchi et al 1994). The origin of an analogous toxic lysoderivative, galactosylsphingosine, in Krabbe disease has been interpreted as aberrant synthesis in the endoplasmic reticulum (Mitsuo et al 1989) by UDP-galactose:ceramide galactosyltransferase (CGT) which synthesizes not only galactocerebroside but also galactosylsphingosine (Morell and Radin 1969). Comparison with Niemann-Pick disease type A featuring by extensive neurolysosomal storage of sphingomyelin showed significant increase in sphingosylphosphorylcholine (lysosphingomyelin) comparable with fetal types of GD II (RodriguezLafrasse and Vanier 1999). However, the neuronal storage pattern is diametrically different from that in GD II (see above)

\section{Intralysosomal retention of uncleaved glucosylceramide}

Macrophages seem to be a remarkable exception in GD, based on their ability to retain the uncleaved GlcCer in their lysosomes and then to display the phenomenon of lysosomal storage. It should be stressed that the lysosomal storage compartment of GCs differs notably from that in storage cells in the broader group of lysosomal storage disorders. In advanced stages, the lysosomal storage compartment in GCs (containing the typical twisted storage tubules embedded in a matrix of varying density) is composed of flattened cisternae enlarged by predominantly $2 \mathrm{D}$ distension. These fre- 
quently express slender tubular expansions of their limiting membrane, suggesting its active propagation throughout the cytosol. In GCs exhibiting a lesser degree of storage, the storage compartment is in the form of narrow cistern-like network of varying density (unpublished personal observation). This arrangement means that induction of the GC structural phenotype does not passively reflect the storage itself (passive 3D volume expansion) but is controlled by factors inherent in the molecular pathology of GlcCer-ase deficiency and is specific for the monocyte-macrophage lineage. The role of the additional (glyco)protein component demonstrated in purified storage tubules (Ebato et al 1980), which contributes to in the storage tubule appearance (Elleder and Smid 1977), remains to be established.

Gaucher cells display a peculiar activation/secretion activity (Hollak et al 1994) and by this, it is suggested, they make a significant contribution to the phenotype (Cox 2001), even if some of the serum factors are produced by other cells (see above). In this way they also differ from storage macrophages in classical lysosomal storage disorders (Elleder and Jirasek 1981). It is tempting to speculate that GlcCer translocation to other cell compartments, especially to the endoplasmic reticulum, might be responsible.

It is generally accepted that the lysosomal load of potential substrates is realized through constitutional phagocytosis of senescent blood elements rich in GlcCer precursors (Brady and King 1973; Naito et al 1988), a mechanism that does not exist in other types of cells. The only analogy may be retinal pigment epithelium, which is permanently active in removing the tips of retinal photoreceptors by phagocytosis (Williams 1995). Its worth mentioning in this connection that retinal pathology has been observed in some GD patients (Gonzalez Rodriguez et al 1992; Rosenthal et al 2000; Wang et al 2005). However, a single report on retinal ultrastructure in GD, showed the presence of GCs but absence of storage in the retinal pigment epithelium (Ueno 1980).

GlcCer lysosomal storage in other cell types has not been described with the exception of rudimentary findings in neurons in GD type II (see above). Discrete lysosomal membranous inclusions (differing from GlcCer tubules) in the respiratory epithelium were described recently in GD II (Shebani et al 2003) and these observations have been personally confirmed (unpublished data). There was a single observation on the excess of ceroid in spleen sinus endothelium and in smooth-muscle cells generally (Yamadori et al 1990). The GlcCer-ase inhibitor, conduritol B epoxide, has been shown to induce lysosomal deposits in cultured cells of human neuroblastoma cell line (SH-SY5Y), but these cells lacked the specific Gaucher morphological phenotype (Prence et al 1996). Despite all these rudimentary findings, the partial sequestration of uncleaved GlcCer in the lysosomes of nonmacrophage elements cannot be excluded. It might start after failure of the extralysosomal transfer of GlcCer.

\section{Enzyme replacement therapy (ERT)}

It is suggested in this report that the positive effect of ERT on organ volume, improvement of patients' quality of life and the elimination of life-threatening consequences of the disease (Rosenthal et al 1995; Weinreb et al 2002) is explainable mainly through the inhibition of the GlcCer translocation mechanism. This means that the cells that are positively affected during ERT do not have a monocyte/macrophage origin, as already suggested (Sato and Beutler 1993). This suggestion is based on the fact that monitoring of the effect of ERT in patients with GD reveals the persistence of GCs (Elleder et al 2005a). Resistance of GCs to ERT might be due to low uptake of the applied enzyme (Sato and Beutler 1993), explainable by the loss of their mannose receptors during the course of their storage transformation (Boven et al 2004). The number of the mannose receptor is not high even in storageunaffected macrophages, in which it can be increased by dexamethasome (Zhu et al 2004). It is suggested here that all other cells, owing to absence of lysosomal storage, may retain their critical receptor equipment and, therefore, preserve their effective receptor-mediated endocytosis. As for the relationship between ERT and GC, it is suggested here that ERT represents prevention of GC induction by its positive influence on monocytes able to endocytose effectively the applied enzyme (Sato and Beutler 1993). This is in accord with the observation of decreased number of GCs during ERT (Rudzki et al 2003). The effect of ERT on the monocyte-histiocytic lineage could thus be better evaluated by measuring the increasing proportion of nonstorage macrophages.

\section{Future studies}

Attention needs to be focused on the mechanisms responsible for the extralysosomal transport of the undegraded GlcCer, which may be identical to the GlcCer recycling pathway from lysosomes to the Golgi apparatus (Trinchera et al 1991). These mechanisms may include some of those suggested for vesicular or intercompartmental glycosphingolipid transport (Holthuis et al 2001; van Meer et al 2003), the latter possibly involving defined roles for specific transport proteins (Metz and Radin 1980; Wong M et al 1984; Yamada and Sasaki 1982).

It is worth exploring whether the NPC1 protein known to be engaged in lipid trafficking and the deficiency of which leads to a variant Niemann-Pick disease (Scott and Ioannou 2004; Vanier and Millat 2003) is upregulated in GlcCer-ase deficiency.

Future studies should specify both the fate of the extralysosomal GlcCer and the mechanisms of its processing, especially the role of neutral non-lysosomal GlcCer-ase, recently identified and characterized (Boot et al 2006), which is not 
deficient in GD (Overkleeft et al 1998; van Weely et al 1993). These studies should specify the relation between the hypothesized GlcCer transfer and the production of its lysoderivative and define the possible role of glucosylceramide deacylase shown to exist in human epidermis (Ishibashi et al 2003)

Future studies should also define factors responsible for retention of uncleaved GlcCer in the lysosomes of macrophages and explain the unique phenotype when GCs are absent (Wenger et al 1983). This so far unique (or misdiagnosed?) variant of GD suggests the existence of the enzyme deficiency without significant lysosomal sequestration of uncleaved GlcCer but with a phenotype based solely, or predominantly, on its transport from lysosomes (GD without GCs). A recent case report of perinatal GD with absence of bone marrow storage cells might belong to this category (Roth et al 2005). Recognition of factors responsible for the lysosomal retention of uncleaved GlcCer might help explain the absence, or exceptional presence, of typical Gaucher cells in experimentally induced GD (Beutler et al 2002; Mizukami et al 2002; Xu et al 2003). According to the hypothesis presented herein, experiments that induce GD should not be limited to the evaluation of induced GlcCer storage, but should always involve the additional evaluation of signs of extralysosomal manifestation of GlcCer-ase deficiency. Also, the evaluation of loading tests, carried out with cultured fibroblasts, should take into account the extralysosomal transfer of uncleaved GlcCer and the extent of its further processing, which should not be interpreted as 'residual' GlcCer-ase activity. Generally speaking, the presented hypothesis may lead to series of experiments evaluating dysfunctions induced by GlcCer transfer in various cell types in GlcCer-ase deficiency.

In the reverse situation, block of GlcCer translocation in GlcCer-ase deficiency should manifest as generalized lysosomal GlcCer storage. This partially resembles the situation in prosaposin deficiency and in Niemann-Pick type C. However, in the former, caused by multiple sphingolipid hydrolase deficiency, due to the absence of all sphingolipid activator proteins (Saps), the high level of GlcCer storage in the visceral region might be explained by the presence of numerous storage macrophages (Elleder et al 2005b), which may even be transformed into Gaucher-type cells (Harzer et al 1989; Hulkova et al 2001). Studies on the distribution of GlcCer in storage-affected cell types in this disorder may bring a final resolution, as it is highly probable that GlcCer is restricted to macrophages. However, different behaviour of storage lysosomes in this complex disorder cannot be excluded.

Studies on extralysosomal transfer of undegraded lipids stored in lysosomes should be extended to other lysosomal storage disorders. In Krabbe disease, galactocerebroside transfer might explain the early death of oligodendrocytes (Wenger et al 2001). In other lysosomal storage disorders, such studies may help to verify whether there is any sig- nificant non-degradation-based turnover of the stored lipids and undegraded nonlipid compounds. A recent report on the unfolded protein response in the endoplasmic reticulum, associated with $\mathrm{GM}_{1}$ lysosomal storage, suggests an important pathogenetic association between storage lysosomes and other cell compartments (Tessitore et al 2004). Studies of this type may contribute to a better evaluation of the biology of storage lysosomes, which seems to be notably different from that of their normal counterparts.

Acknowledgment The project was supported by the Ministry of Education of the Czech Republic (project no. MSM 0021620806).

\section{References}

Adachi M, Volk BW (1977) Gaucher disease in mice induced by conduritol-B-epoxide: morphologic features. Arch Pathol Lab Med 101: 255-259.

Adachi M, Wallace BJ, Schneck L, et al (1967) Fine structure of central nervous system in early infantile Gaucher's disease. Arch Pathol 83: $513-526$

Aghion H (1934) La maladie de Gaucher dans l' enfance (Thesis, Paris) Barton NW, Rosenberg A (1975) Metabolism of glucosyl $\left[1-{ }^{3} \mathrm{H}\right]$ ceramide by human skin fibroblasts from normal and glucosylceramidotic subjects. J Biol Chem 250: 3966-3971.

Beighton P, Goldblatt J, Sacks S (1982) Bone involvement in Gaucher disease. In: Desnick R, Gatt S, Grabowski G, eds. Gaucher Disease: A Century of Delineation and Research, Proceedings of the First International Symposium on Gaucher Disease, New York, Alan R. Liss, 107-129.

Beutler E, Grabowski G (2001) Gaucher disease. In: Scriver CR, Beaudet al, Sly WS, Valle D, eds; Childs B, Kinzler KW, Vogelstein B, assoc, eds. The Metabolic and Molecular Bases of Inherited Disease, 8th edn. New York: McGraw-Hill, 3635-3668.

Beutler E, West C, Torbett BE, et al (2002) A chimeric mouse model of Gaucher disease. Mol Med 8: 247-250.

Bieberich E (2004) Integration of glycosphingolipid metabolism and cell-fate decisions in cancer and stem cells: review and hypothesis. Glycoconj J 21: 315-327.

Bodamer OA, Church HJ, Cooper A, et al (2002) Variant Gaucher disease characterized by dysmorphic features, absence of cardiovascular involvement, laryngospasm, and compound heterozygosity for a novel mutation (D409H/C16S) Am J Med Genet 109: 328331 .

Bodennec J, Pelled D, Riebeling C, et al (2002) Phosphatidylcholine synthesis is elevated in neuronal models of Gaucher disease due to direct activation of CTP:phosphocholine cytidylyltransferase by glucosylceramide. FASEB J 16: 1814-1816.

Boot RG, Verhoek M, Donker-Koopman WE, et al (2006) Identification and Characterization of the Non-lysosomal Glucosylceramidase. Cambridge, UK: European Working Group on Gaucher Disease.

Boven LA, van Meurs M, Boot RG, et al (2004) Gaucher cells demonstrate a distinct macrophage phenotype and resemble alternatively activated macrophages. Am J Clin Pathol 122: 359-369.

Brady R, King F (1973) Gaucher's disease. In: Hers H, Hoof Fv, eds. Lysosomes and Storage Diseases. New York, London: Academic Press; 381-394.

Casal JA, Lacerda L, Perez LF, et al (2002) Relationships between serum markers of monocyte/macrophage activation in type 1 Gaucher's disease. Clin Chem Lab Med 40: 52-55. 
Cervos-Navarro J, Zimmer C (1990) Light microscopic and ultrastructural study on CNS lesions in infantile Gaucher's disease. Clin Neuropathol 9: 310-313.

Conradi NG, Kalimo H, Sourander P (1988) Reactions of vessel walls and brain parenchyma to the accumulation of Gaucher cells in the Norrbottnian type (type III) of Gaucher disease. Acta Neuropathol (Berl) 75: 385-390.

Conradi N, Kyllerman M, Mansson JE, et al (1991) Late-infantile Gaucher disease in a child with myoclonus and bulbar signs: neuropathological and neurochemical findings. Acta Neuropathol (Berl) 82: 152-157.

Cox TM (2001) Gaucher disease: understanding the molecular pathogenesis of sphingolipidoses. J Inherit Metab Dis 24(Supplement 2): 106-121; discussion 187-108.

Cox TM (2005) Substrate reduction therapy for lysosomal storage diseases. Acta Paediatr Suppl 94: 69-75; discussion 57.

Cox TM, Schofield JP (1997) Gaucher's disease: clinical features and natural history. Baillières Clin Haematol 10: 657-689.

Datta SC, Radin NS (1988) Stimulation of liver growth and DNA synthesis by glucosylceramide. Lipids 23: 508-510.

Deegan PB, Moran MT, McFarlane I, et al (2005) Clinical evaluation of chemokine and enzymatic biomarkers of Gaucher disease. Blood Cells Mol Dis 35: 259-267.

Desnick R, Gatt S, Grabowski G (1982) Gaucher Disease: A Century of Delineation and Research, Proceedings of the First International Symposium on Gaucher Disease. New York, Alan R. Liss.

Ebato H, Abe T, Yamakawa T, et al (1980) Characterization of the cytoplasmic inclusion bodies of the spleens from patients with adult form Gaucher's disease. J Biochem (Tokyo) 88: 17651772 .

Eblan MJ, Goker-Alpan O, Sidransky E (2005) Perinatal lethal Gaucher disease: a distinct phenotype along the neuronopathic continuum. Fetal Pediatr Pathol 24: 205-222.

Edwards WD, Hurdey HP, 3rd, Partin JR (1983) Cardiac involvement by Gaucher's disease documented by right ventricular endomyocardial biopsy. Am J Cardiol 52: 654.

Elleder M (1989) Niemann-Pick disease. Pathol Res Pract 185: 293328.

Elleder M, Jirasek A (1981) Histochemical and ultrastructural study of Gaucher cells. Acta Neuropathol Suppl (Berl) 7: 208-210.

Elleder M, Smid F (1977) Lysosomal non-lipid component of Gaucher's cells. Virchows Arch B Cell Pathol 26: 133-138.

Elleder M, Dobrovolny R, Keslova J, et al (2005a) ERT in Fabry and Gaucher Diseases. Reality at the Cellular Level, 15th ESGLD Workshop, Oslo, Norway, ESGLD.

Elleder M, Jerabkova M, Befekadu A, et al (2005b) Prosaposin deficiency - a rarely diagnosed, rapidly progressing, neonatal neurovisceral lipid storage disease. Report of a further patient. $\mathrm{Neu}$ ropediatrics 36: 171-180.

Fiore CE, Barone R, Pennisi P, et al (2002) Bone ultrasonometry, bone density, and turnover markers in type 1 Gaucher disease. $J$ Bone Miner Metab 20: 34-38.

Fox H, McCarthy P, Andre-Schwartz J, et al (1984) Gaucher's disease and chronic lymphocytic leukemia. Possible pathogenetic link between Gaucher's disease and B-cell proliferations? Cancer 54: 312-314

George R, McMahon J, Lytle B, et al (2001) Severe valvular and aortic arch calcification in a patient with Gaucher's disease homozygous for the D409H mutation. Clin Genet 59: 360-363.

Ginzburg L, Kacher Y, Futerman AH (2004) The pathogenesis of glycosphingolipid storage disorders. Semin Cell Dev Biol 15: 417431.

Gonzalez Rodriguez MJ, Pintado Conde H, Lopez Nieto C, Capdevita Puerta A, Torres Carrete JP (1992) Retinal involvement in Gaucher's disease [In French]. J Fr Ophthalmol 15: 185-190.
Grafe M, Thomas C, Schneider J, et al (1988) Infantile Gaucher's disease: a case with neuronal storage. Ann Neurol 23: 300-303.

Hara A, Radin NS (1979) Enzymic effects of beta-glucosidase destruction in mice. Changes in glucuronidase levels. Biochim Biophys Acta 582: 423-433.

Harzer K, Paton BC, Poulos A, et al (1989) Sphingolipid activator protein deficiency in a 16-week-old atypical Gaucher disease patient and his fetal sibling: biochemical signs of combined sphingolipidoses. Eur J Pediatr 149: 31-39.

Hernandez F, Bueno M (1973) Infantile neurological Gaucher's disease in three siblings. An ultrastructural study. Virchows Arch A Pathol Pathol Anat 360: 27-32.

Hollak CE, van Weely S, van Oers MH, et al (1994) Marked elevation of plasma chitotriosidase activity. A novel hallmark of Gaucher disease. J Clin Invest 93: 1288-1292.

Holleran WM, Ginns EI, Menon GK, et al (1994) Consequences of beta-glucocerebrosidase deficiency in epidermis. Ultrastructure and permeability barrier alterations in Gaucher disease. $J$ Clin Invest 93: 1756-1764.

Holthuis JC, Pomorski T, Raggers RJ, et al (2001) The organizing potential of sphingolipids in intracellular membrane transport. Physiol $\operatorname{Rev}$ 81: 1689-1723.

Hulkova H, Cervenkova M, Ledvinova J, et al (2001) A novel mutation in the coding region of the prosaposin gene leads to a complete deficiency of prosaposin and saposins, and is associated with a complex sphingolipidosis dominated by lactosylceramide accumulation. Hum Mol Genet 10: 927-940.

Inui K, Yanagihara K, Otani K, et al (2001) A new variant neuropathic type of Gaucher's disease characterized by hydrocephalus, corneal opacities, deformed toes, and fibrous thickening of spleen and liver capsules. J Pediatr 138: 137-139.

Ishibashi M, Arikawa J, Okamoto R, et al (2003) Abnormal expression of the novel epidermal enzyme, glucosylceramide deacylase, and the accumulation of its enzymatic reaction product, glucosylsphingosine, in the skin of patients with atopic dermatitis. Lab Invest 83: $397-408$.

Jmoudiak M, Futerman AH (2005) Gaucher disease: pathological mechanisms and modern management. Br J Haematol 129: 178-188.

Korkotian E, Schwarz A, Pelled D, et al (1999) Elevation of intracellular glucosylceramide levels results in an increase in endoplasmic reticulum density and in functional calcium stores in cultured neurons. J Biol Chem 274: 21673-21678.

Lee RE (1982) The Pathology of Gaucher Disease. In: Desnick R, Gatt $\mathrm{S}$, Grabowski GA, eds. Gaucher Disease: A Century of Delineation and Research. New York: Alan R Liss, 177-217.

Lipson AH, Rogers M, Berry A (1991) Collodion babies with Gaucher's disease-a further case. Arch Dis Child 66: 667.

Lloyd OC, Norman RM, Urich H (1956) The neuropathology of infantile Gaucher's disease. J Pathol Bacteriol 72: 121-131.

Lloyd-Evans E, Pelled D, Riebeling C, et al (2003) Lysoglycosphingolipids mobilize calcium from brain microsomes via multiple mechanisms. Biochem J 375: 561-565.

Marsh NL, Elias PM, Holleran WM (1995) Glucosylceramides stimulate murine epidermal hyperproliferation. J Clin Invest 95: $2903-$ 2909.

Metz RJ, Radin NS (1980) Glucosylceramide uptake protein from spleen cytosol. J Biol Chem 255: 4463-4467.

Mignot C, Gelot A, Bessieres B, et al (2003) Perinatal-lethal Gaucher disease. Am J Med Genet A 120: 338-344.

Mistry PK, Sirrs S, Chan A, et al (2002) Pulmonary hypertension in type 1 Gaucher's disease: genetic and epigenetic determinants of phenotype and response to therapy. Mol Genet Metab 77: 91-98.

Mitsuo K, Kobayashi T, Shinnoh N, et al (1989) Biosynthesis of galactosylsphingosine (psychosine) in the twitcher mouse. Neurochem Res 14: 899-903. 
Mizukami H, Mi Y, Wada R, et al (2002) Systemic inflammation in glucocerebrosidase-deficient mice with minimal glucosylceramide storage. J Clin Invest 109: 1215-1221.

Moran MT, Schofield JP, Hayman AR, et al (2000) Pathologic gene expression in Gaucher disease: up-regulation of cysteine proteinases including osteoclastic cathepsin K. Blood 96: 19691978.

Morell P, Radin NS (1969) Synthesis of cerebroside by brain from uridine diphosphate galactose and ceramide containing hydroxy fatty acid. Biochemistry 8: 506-512.

Naito M, Takahashi K, Hojo H (1988) An ultrastructural and experimental study on the development of tubular structures in the lysosomes of Gaucher cells. Lab Invest 58: 590-598.

Nilsson O, Mansson JE, Hakansson G, et al (1982) The occurrence of psychosine and other glycolipids in spleen and liver from the three major types of Gaucher's disease. Biochim Biophys Acta 712: 453-463.

Orvisky E, Sidransky E, McKinney CE, et al (2000) Glucosylsphingosine accumulation in mice and patients with type 2 Gaucher disease begins early in gestation. Pediatr Res 48: 233 237.

Orvisky E, Park JK, LaMarca ME, et al (2002) Glucosylsphingosine accumulation in tissues from patients with Gaucher disease: correlation with phenotype and genotype. Mol Genet Metab 76: 262 270.

Overkleeft HS, Renkema GH, Neele J, et al (1998) Generation of specific deoxynojirimycin-type inhibitors of the non-lysosomal glucosylceramidase. J Biol Chem 273: 26522-26527.

Parkin JL, Brunning RD (1982) Pathology of the Gaucher cell. In: Desnick R, Gatt S, Grabowski GA, eds. Gaucher Disease: A Century of Delineation and Research. New York, Alan R Liss, 151176.

Pelled D, Trajkovic-Bodennec S, Lloyd-Evans E, et al (2005) Enhanced calcium release in the acute neuronopathic form of Gaucher disease. Neurobiol Dis 18: 83-88.

Platzker Y, Fisman EZ, Pines A, et al (1985) Unusual echocardiographic pattern in Gaucher's disease. Cardiology 72: 144-146.

Prence EM, Chaturvedi P, Newburg DS (1996) In vitro accumulation of glucocerebroside in neuroblastoma cells: a model for study of Gaucher disease pathobiology. J Neurosci Res 43: 365-371.

Rodriguez-Lafrasse C, Vanier MT (1999) Sphingosylphosphorylcholine in Niemann-Pick disease brain: accumulation in type A but not in type B. Neurochem Res 24: 199-205.

Ron I, Horowitz M (2005) ER retention and degradation as the molecular basis underlying Gaucher disease heterogeneity. Hum Mol Genet 14: 2387-2398.

Rosenthal DI, Doppelt SH, Mankin HJ, et al (1995) Enzyme replacement therapy for Gaucher disease: skeletal responses to macrophage-targeted glucocerebrosidase. Pediatrics 96: 629-637.

Rosenthal G, Wollstein G, Klemperer I, et al (2000) Macular changes in type I Gaucher's disease. Ophthalmic Surg Lasers 31: 331-333.

Roth P, Sklower Brooks S, Potaznik D, et al (2005) Neonatal Gaucher disease presenting as persistent thrombocytopenia. J Perinatol 25: 356-358.

Rudzki Z, Okon K, Machaczka M, et al (2003) Enzyme replacement therapy reduces Gaucher cell burden but may accelerate osteopenia in patients with type I disease-a histological study. Eur $J$ Haematol 70: 273-281.

Saito M, Rosenberg A (1985) The fate of glucosylceramide (glucocerebroside) in genetically impaired (lysosomal beta-glucosidase deficient) Gaucher disease diploid human fibroblasts. J Biol Chem 260: 2295-2300.

Sato Y, Beutler E (1993) Binding, internalization, and degradation of mannose-terminated glucocerebrosidase by macrophages. J Clin Invest 91: 1909-1917.
Schmitz M, Alfalah M, Aerts JM, et al (2005) Impaired trafficking of mutants of lysosomal glucocerebrosidase in Gaucher's disease. Int J Biochem Cell Biol 37: 2310-2320.

Schueler UH, Kolter T, Kaneski CR, et al (2003) Toxicity of glucosylsphingosine (glucopsychosine) to cultured neuronal cells: a model system for assessing neuronal damage in Gaucher disease type 2 and 3. Neurobiol Dis 14: 595-601.

Schuchman E, Desnick R (2001) Niemann-Pick disease types A and B: acid sphingomyelinase deficiencies. In: Scriver CR, Beaudet al, Sly WS, Valle D, eds; Childs B, Kinzler KW, Vogelstein B, assoc, eds. The Metabolic and Molecular Bases of Inherited Disease, 8th edn. New York: McGraw-Hill, 3589-3610.

Scott C, Ioannou YA (2004) The NPC1 protein: structure implies function. Biochim Biophys Acta 1685: 8-13.

Shayman JA, Deshmukh GD, Mahdiyoun S, et al (1991) Modulation of renal epithelial cell growth by glucosylceramide. Association with protein kinase C, sphingosine, and diacylglycerol. J Biol Chem 266: 22968-22974.

Shebani E, Johannesson M, Stromberg B, et al (2003) A patient with type 2 Gaucher's disease with respiratory disease. J Pediatr 142: 209-210.

Sherer DM, Metlay LA, Sinkin RA, et al (1993) Congenital ichthyosis with restrictive dermopathy and Gaucher disease: a new syndrome with associated prenatal diagnostic and pathology findings. Obstet Gynecol 81: 842-844.

Sidransky E (2004) Gaucher disease: complexity in a "simple" disorder. Mol Genet Metab 83: 6-15.

Sidransky E, Sherer DM, Ginns EI (1992) Gaucher disease in the neonate: a distinct Gaucher phenotype is analogous to a mouse model created by targeted disruption of the glucocerebrosidase gene. Pediatr Res 32: 494-498.

Smith RL, Hutchins GM, Sack GH Jr., et al (1978) Unusual cardiac, renal and pulmonary involvement in Gaucher's disease. Intersitial glucocerebroside accumulation, pulmonary hypertension and fatal bone marrow embolization. Am J Med 65: 352360 .

Stone DL, Tayebi N, Coble C, et al (2000) Cardiovascular fibrosis, hydrocephalus, ophthalmoplegia, and visceral involvement in an American child with Gaucher disease. J Med Genet 37: E40.

Stowens DW, Teitelbaum SL, Kahn AJ, et al (1985) Skeletal complications of Gaucher disease. Medicine (Baltimore) 64: 310-322.

Suzuki K (1982) Glucosylceramide and related compounds in normal tissues and in Gaucher disease. In: Desnick R, Gatt S, Grabowski G, eds. Gaucher Disease: A Century of Delineation and Research, Proceedings of the First International Symposium on Gaucher Disease. New York: Alan R Liss, 219-230.

Tayebi N, Walker J, Stubblefield B, et al (2003) Gaucher disease with parkinsonian manifestations: does glucocerebrosidase deficiency contribute to a vulnerability to parkinsonism? Mol Genet Metab 79: $104-109$.

Tessitore A, del P Martin M, Sano R, et al (2004) GM1-gangliosidemediated activation of the unfolded protein response causes neuronal death in a neurodegenerative gangliosidosis. Mol Cell 15: 753-766.

Theise ND, Ursell PC (1990) Pulmonary hypertension and Gaucher's disease: logical association or mere coincidence? Am J Pediatr Hematol Oncol 12: 74-76.

Torloni MR, Franco K, Sass N (2002) Gaucher's disease with myocardial involvement in pregnancy. Sao Paulo Med J 120: 90-92.

Trinchera M, Fabbri M, Ghidoni R (1991) Topography of glycosyltransferases involved in the initial glycosylations of gangliosides. J Biol Chem 266: 20907-20912.

Tybulewicz VL, Tremblay ML, LaMarca ME, et al (1992) Animal model of Gaucher's disease from targeted disruption of the mouse glucocerebrosidase gene. Nature 357: 407-410. 
Uchida Y, Murata S, Schmuth M, et al (2002) Glucosylceramide synthesis and synthase expression protect against ceramide-induced stress. J Lipid Res 43: 1293-1302.

Ueno H, Ueno S, Matsuo N, Kajitani T, Fujiwara J (1980) Electron microscopic study of Gaucher cells in the eye. Jpn J Ophthalmol 24: $75-81$.

Uyama E, Terasaki T, Watanabe S, et al (1992) Type 3 GM1 gangliosidosis: characteristic MRI findings correlated with dystonia. Acta Neurol Scand 86: 609-615.

van Meer G, Wolthoorn J, Degroote S (2003) The fate and function of glycosphingolipid glucosylceramide. Philos Trans $R$ Soc Lond B Biol Sci 358: 869-873.

van Weely S, Brandsma M, Strijland A, et al (1993) Demonstration of the existence of a second, non-lysosomal glucocerebrosidase that is not deficient in Gaucher disease. Biochim Biophys Acta 1181: 55-62.

Vanier MT, Millat G (2003) Niemann-Pick disease type C. Clin Genet 64: $269-281$.

Wang TJ, Chen MS, Shih YF, et al (2005) Fundus abnormalities in a patient with type I Gaucher's disease with 12-year follow-up. Am J Ophthalmol 139: 359-362.

Weinreb NJ, Charrow J, Andersson HC, et al (2002) Effectiveness of enzyme replacement therapy in 1028 patients with type 1 Gaucher disease after 2 to 5 years of treatment: a report from the Gaucher Registry. Am J Med 113: 112-119.

Wenger DA, Roth S, Kudoh T, et al (1983) Biochemical studies in a patient with subacute neuropathic Gaucher disease without visceral glucosylceramide storage. Pediatr Res 17: 344-348.

Wenger D, Suzuki K, Suzuki Y, et al (2001) Galactosylceramide lipidosis: globoid cell leukodystrophy (Krabbe disease). In: Scriver CR, Beaudet al, Sly WS, Valle D, eds; Childs B, Kinzler KW, Vogelstein B, assoc, eds. The Metabolic and Molecular Bases of Inherited Disease, 8th edn. New York: McGraw-Hill, 36693694.

Wenstrup RJ, Roca-Espiau M, Weinreb NJ, et al (2002) Skeletal aspects of Gaucher disease: a review. Br J Radiol 75(Supplement 1): A212.
Willemsen R, Tybulewicz V, Sidransky E, et al (1995) A biochemical and ultrastructural evaluation of the type 2 Gaucher mouse. Mol Chem Neuropathol 24: 179-192.

Williams PL (1995) Nervous system. Accessory visual apparatus. In: Williams PL, ed. Gray's Anatomy. The Anatomical Basis of Medicine and Surgery. London: Churchill Livingstone, 1338.

Wilson ER, Barton NW, Barranger JA (1985) Vascular involvement in type 3 neuronopathic Gaucher's disease. Arch Pathol Lab Med 109: $82-84$.

Wong K, Sidransky E, Verma A, et al (2004) Neuropathology provides clues to the pathophysiology of Gaucher disease. Mol Genet Metab 82: 192-207.

Wong M, Brown RE, Barenholz Y, et al (1984) Glycolipid transfer protein from bovine brain. Biochemistry 23: 6498-6505.

Xu YH, Quinn B, Witte D, et al (2003) Viable mouse models of acid beta-glucosidase deficiency: the defect in Gaucher disease. Am J Pathol 163: 2093-2101.

Yamada K, Sasaki T (1982) A rat brain cytosol protein which accelerates the translocation of galactosylceramide, lactosylceramide and glucosylceramide between membranes. Biochim Biophys Acta 687: 195-203.

Yamadori I, Morikawa T, Kobayashi S, et al (1990) Gaucher's disease type I. Report of a case with prominent deposition of ceroid in splenic endothelial cells and intestinal smooth muscle fibers. Acta Pathol Jpn 40: 425-430.

Yamaguchi Y, Sasagasako N, Goto I, et al (1994) The synthetic pathway for glucosylsphingosine in cultured fibroblasts. J Biochem (Tokyo) 116: 704-710.

Zhao H, Grabowski GA (2002) Gaucher disease: perspectives on a prototype lysosomal disease. Cell Mol Life Sci 59: 694-707.

Zhu Y, Li X, Schuchman E, et al (2004) Dexamethasone-mediated upregulation of the mannose receptor improves the delivery of recombinant glucocerebrosidase to Gaucher macrophages. J Pharmacol Exp Ther 308: 705-711.

Zimran A, Liphshitz I, Barchana M, et al (2005) Incidence of malignancies among patients with type I Gaucher disease from a single referral clinic. Blood Cells Mol Dis 34: 197-200. 